\title{
Approximation to the Laser Floating Zone preparation of high temperature BSCCO superconductors by DSC.
}

M.C. Mayoral ${ }^{* a}$, J.M. Andrés ${ }^{\text {a }}$, M.T. Bona ${ }^{\text {a }}$, L.A. Angurel ${ }^{\text {b }}$, E. Natividad ${ }^{\text {b }}$

*: Corresponding author.

a Instituto de Carboquímica, CSIC. Miguel Luesma Castán, n. 4. 50018-Zaragoza (Spain)

Fax no.: 34976733318

Email address: mayoral@carbon.icb.csic.es

b Departamento de Ciencia y Tecnología de Materiales y Fluidos, Instituto de Ciencia de Materiales de Aragón (CSIC-Universidad de Zaragoza), María de Luna, 3, 50018-Zaragoza (Spain)

ABSTRACT.

Differential scanning calorimetry (DSC) has been used to simulate laser fusion of ceramic precursors to prepare BSCCO high temperature superconducting materials. At fast heating rates, typical of the laser floating zone, the energy required for complete melting of the precursor increases with the $\mathrm{Bi}$ to $\mathrm{Sr}+\mathrm{Ca}$ ratio, in agreement with the critical current results obtained. At low heating rates, solid state reactions involving ionic rearrangements take place before incongruent melting. These changes can be divided in up to three processes and can be quantified from calorimetric measurements. Lower heating rates and isothermal experiments allow detailed visualization of the ionic arrangements taking place. The results prove that the mechanism of the final phase formation is dependent on the fabrication procedure.

KEYWORDS: DSC, BSCCO superconductors, solid diffusion, precursor composition. 


\section{INTRODUCTION}

The Bi-Sr-Ca-Cu-O (BSCCO) compounds, whose superconductivity was first reported by Maeda et al. [1], are one of the two most important families of high temperature superconductors with technological relevance. They are highly anisotropic layered ceramics with a structure of perovskite crystals, in which the presence of $\mathrm{CuO}_{2}$ planes, usually set as $a-b$ planes, is essential for superconductivity. Precisely, the fact that the current mainly flows in the direction perpendicular to the $c$-axis makes to require complex fabrication techniques that introduce a high degree of texture in these granular materials, and their critical current density, $J_{c}$, is heavily dependent on the processing. The fabrication methods are in continuous development, and nowadays BSCCO-based materials are achieved in a wide range of shapes (thin and thick films, tapes, wires, bars, tubes...).

BSCCO superconductor specimens are mainly fabricated from superconducting powders. These powders are often obtained by solid-state reaction [2], due to the simplicity and the reduced infrastructure required for this method, although other techniques, as coprecipitation [3] or sol-gel [4], are also used. The most common precursors for solid-state reaction are the $\mathrm{Bi}_{2} \mathrm{O}_{3}, \mathrm{SrCO}_{3}, \mathrm{CaCO}_{3}$ and $\mathrm{CuO}$, mixed in the adequate proportions. This mixture is then subjected to successive stages of thermochemical reaction and grinding, to allow good mixing and diffusion.

The Laser Floating Zone (LFZ) method [5], which consists in the laser-induced generation and movement of a small molten zone along a polycrystalline solid, has proved to be a fast, controlled and reproducible technique for the growth of highly textured BSCCO ceramics. In effect, the axial thermal gradient generated by the laser induces the appropriate orientation of the grains within the solidified material. With this method, good-performance thin rods of $\mathrm{Bi}_{2} \mathrm{Sr}_{2} \mathrm{CaCu}_{2} \mathrm{O}_{8+\delta}(\mathrm{Bi}-2212)$ of up to $20 \mathrm{~cm}$ in length and 1.5-2 $\mathrm{mm}$ in diameter have been obtained using as solid precursor cylinders made of pressed superconducting powders. Obviously, the LFZ-growth parameters, such as the growth rate, the temperature gradient or the incident laser power, influence the microstructure of the as-grown sample, as well as the microstructure and properties of the annealed rods. But the characteristics of the superconducting powders (grain size, present phases, average composition) are also of great importance, since the LFZ-process performance will also depend on the melting and solidification behaviour of these powders.

Previous studies on the influence of the precursor powder composition in the microstructure of LFZ-textured thin rods [6, 7] revealed that, under similar processing conditions, Bi-poor starting mixtures give rise to samples with a more homogeneous composition of $\mathrm{Bi}-2212$ grains and better superconducting properties. In effect, the modifications in the melting and solidification processes induced by the differences between precursor powders produce as-grown samples with a more adequate phase composition and distribution, which yields, after the annealing, a more homogeneous 
Bi-2212 phase composition. These results have stimulated further studies on the influence of the powder composition in the laser melting process.

The use of DTA/TG for the study of BSCCO superconductors has already been presented by several authors [8-13]. These measurements have been useful for the detection of secondary phases arising from different processing conditions, for the study of the melting point variations with phase composition, for the determination of annealing temperatures or even for detecting the presence of intermediate phases during the formation of the final product. However, there are fewer examples in which DTA has been employed for the characterisation of fast melting processes and the relationship of the initial powder composition with the so-obtained as-grown and annealed microstructures and final properties.

In the present work, DTA has been used for the detection of different phases and the characterisation of the laser melting behaviour of precursor powders fabricated by solid-state reaction of adequate oxides and carbonates with different average compositions. The studied compositions have been derived by an unfinished sequential optimisation process that departed from the stoichiometry $(\mathrm{Bi}: \mathrm{Sr}: \mathrm{Ca}: \mathrm{Cu})=(2: 2: 1: 2)$ and that was focused on improving the current transport properties of the final superconductor rods. It must be mentioned that, during the optimisation process, the $\mathrm{Cu}$ content was fixed to 2, since it is well known that $\mathrm{Cu}$ does not play an important role in the Bi2212 solid solution [8, 14]. However, as it is generally agreed that the Sr and Ca can substitute each other to some extent, and that $\mathrm{Bi}$ can substitute $\mathrm{Sr}$ and/or $\mathrm{Ca}$ (but not the contrary), the $\mathrm{Bi}$, $\mathrm{Sr}$ and $\mathrm{Ca}$ contents were varied.

\section{EXPERIMENTAL}

The starting materials consisted of high-purity $\mathrm{Bi}_{2} \mathrm{O}_{3}, \mathrm{CaCO}_{3}, \mathrm{SrCO}_{3}$ and $\mathrm{CuO}$ powders, mixed and ground in the appropriate molar ratios, and subjected to three successive $12 \mathrm{~h}$ calcination cycles at 790, 830 and $845^{\circ} \mathrm{C}$, with intermediate grinding to homogenise the material. From these powders, precursor cylinders for the LFZ growth were fabricated by isostatic pressing (200 MPa for 2 minutes). Afterwards, these cylinders were LFZ-textured with similar conditions, described elsewhere [7], and the obtained as-grown material was annealed in air at $830^{\circ} \mathrm{C}$ for $60 \mathrm{~h}$ to develop the Bi-2212 phase. As mentioned before, the $\mathrm{Cu}$ content of all precursor powders was fixed to 2, while the $\mathrm{Bi}$, $\mathrm{Sr}$ and $\mathrm{Ca}$ contents ranged between 1.56-2.21, 1.72-2.16 and 0.87-1.10, respectively. The initial composition of each precursor and the engineering critical current density, $J_{c}^{e n g}$, values of the final rods are collected in Table 1.

Differential Scanning Calorimetry was performed using a TA SDT 2960 system, which allows simultaneous registry of weight loss and heat flow changes along programmed temperature scans. 
DSC was calibrated with sapphire standard and sensitivity in measuring melting enthalpies is tested with silver and aluminium standards. Samples of about $15 \mathrm{mg}$ were laid onto the tared Pt pans and air was used as the purge gas at a flow of $90 \mathrm{ml} \mathrm{min}^{-1}$. Two main heat treatments were applied to the precursors: a heating ramp of $50^{\circ} \mathrm{C} \mathrm{min}^{-1}$ to $1150^{\circ} \mathrm{C}$, to simulate the fast heat input at the $\mathrm{LFZ}$ set-up, and a heating ramp of $5^{\circ} \mathrm{C} \mathrm{min}^{-1}$ to $930^{\circ} \mathrm{C}$, for a thorough study of thermal events. Moreover, special heat treatments (heating ramp of $0.1^{\circ} \mathrm{C} \mathrm{min}$, isothermal stages) were applied to those samples showing distinctive behaviours.

The endothermic fusion can be quantified through the integration of the DSC peaks, which allows obtaining the enthalpy of fusion in $\mathrm{J}^{-1}$. The calculation of the enthalpy changes has an estimated experimental error of $2 \%$ at the studied conditions, although the uncertainty in the determination of the baseline for integration may add some errors due to the peak shape.

\section{RESULTS}

The inspection of the powders by SEM-EDX showed that they were complex materials containing Bi2212 and $\mathrm{Bi}_{2} \mathrm{Sr}_{2} \mathrm{CuO}_{6}(\mathrm{Bi}-2201)$ as the main phases and other $\mathrm{Bi}$-free oxides as $\left(\mathrm{Sr}_{\mathrm{x}} \mathrm{Ca}_{1-\mathrm{x}}\right)_{14} \mathrm{Cu}_{21} \mathrm{O}_{42}$ or $\mathrm{CuO}$ in different proportions. The optimisation design allowed to infer a clear trend: high $J_{c}^{\text {eng }}$ values are obtained when $\mathrm{Bi}$ was reduced with respect to the original proportion, leading to nearly linear dependence of the measured $J_{c}^{e n g}$ with the ratio $\mathrm{Bi} /(\mathrm{Sr}+\mathrm{Ca})$ [15]. The first aim of the present calorimetric study of the precursor powders was to investigate the thermal behaviour of each powder as a function of initial composition, due to the experimental differences observed in the laser floating zone: the Bi-poor precursors required the use of additional laser power in the LFZ growth process to ensure a complete melting [15]. On the other hand, provided that the electric performance of the final annealed rod could be related to the melting process, it is interesting to study each precursor in differential scanning calorimetry. In this way, thermal events involving heat flow changes (solid state reaction, dissolution, melting) are easily recorded.

\section{Simulation of laser melting: fast heating ramp.}

While it is impossible to simulate the high thermal gradient generated by the laser in the rods, an attempt was carried out to mimic the precursor behaviour using the fastest heating rate possible in our device with these materials. In previous works related to aluminosilicate transformations, the maximum heating ramp that the system allowed with reproducible results was $80^{\circ} \mathrm{C} \mathrm{min}{ }^{-1}$ [16], but for the BSCCO materials, the heat flow profile showed problems in recovering the baseline. In this way, $50^{\circ} \mathrm{C} \mathrm{min}^{-1}$ was chosen for the fusion experiments to calculate heat flow involved in fast incongruent melting. As it is shown in Figure 1, three different profile types are obtained: a single peak with a 
shoulder at the low temperature side, which could indicate a low-temperature melting phase (exp5 in the figure as example, and exp1, 2, 3 and 4); a single peak with a smaller contribution of the low temperature shoulder (exp7 in the figure as example, and exp6, exp11); and a negligible presence of it (exp11 in the figure as example, and exp13). Nevertheless, the most striking differences appear in the peak offset: the endothermic peak tails indicate the presence of species of high melting point for those precursor with a low Bi content.

DSC quantification of energy involved in the endothermic peaks is presented in joules per gram in Figure 2. It is possible to see that melting enthalpies vary with initial precursor stoichometry: the higher the Bi content, the lower the melting enthalpy. These results indicate that precursors poor in $\mathrm{Bi}$ would require higher temperatures to melt in furnace systems, or, as in this case, the power requirements of laser output would be higher to reach complete melting, as confirmed elsewhere [15]. In this case of fast heating ramp, where the endothermic phenomena are delayed in some degrees, peak minima values resulted more reliable to determine the reaction peak temperature than the onset or offset temperatures. The relationship of initial composition versus peak minima is shown in Figure 3. There are works in the literature that show a decrease in melting point with the addition of $\mathrm{Pb}$ and $\mathrm{Sn}$, supporting the thesis of the formation of a liquid phase which accelerates the diffusion of reactants [9]. In the present work, just small variations in $\mathrm{Bi}$ content in stoichiometry of $\mathrm{Bi}-2212$ phase present similar trends: those precursors rich in Bi showed lower reaction temperatures.

The main inference from these results is that a reduction in $\mathrm{Bi} /(\mathrm{Sr}+\mathrm{Ca})$ ratio involves not only changes in peak temperature (in a 7 degrees range) but also a limitation of liquid phase formation. The mechanism and extent of this constrainment cannot be described from DSC profiles obtained at fast heating ramps, so the thermal history of precursor was deeply studied at $5^{\circ} \mathrm{C} \min ^{-1}$.

\section{Thermal history of precursors at $5^{\circ} \mathrm{C} \mathrm{min}^{-1}$.}

Slow heating ramps are often preferred for characterization and melting point calculations because overlaping of thermal phenomena is avoided. In Figure 4, it is possible to see how different the thermal profile of precursor exp5 is from that profile showed in Figure 1. A heating ramp of $5^{\circ} \mathrm{C} \min ^{-1}$ allows the deconvolution of the fusion phenomenon into three different endothermic peaks. This behaviour is seen as well for precursors exp1, exp2 and exp3. At a first glance, it would indicate that there are at least three different species that melt at different temperatures, provided that the onset temperature is a thermodynamic parameter characteristic of each substance. So, for these samples, it could be inferred that a small part of the mass melts between $865^{\circ}-870^{\circ} \mathrm{C}$, another fraction melts between $875^{\circ}$ and $885^{\circ}$, and the greater portion melts between $885^{\circ}$ and $895^{\circ} \mathrm{C}$. On the other hand, the first peak does not appear (or is negligible) in the rest of the samples. In previous works focused in 
$\mathrm{Bi}_{2} \mathrm{~Pb}_{1-\mathrm{x}} \mathrm{Sn}_{\mathrm{x}} \mathrm{Sr}_{2} \mathrm{Ca}_{2} \mathrm{Cu}_{3} \mathrm{O}_{\mathrm{y}}$ superconductors [13], similar peaks before the main one were described, and assigned to the formation of liquid phase or the reaction between solid state precursors. In fact, exp9 and exp10, poor in $\mathrm{Bi}$, present only the high temperature peak. When the fusion phenomena is the sum of overlapped peaks, the analysis software can decompose them into the different amount of energy absorbed (in Joules) for each single peak. The example of total amount of heat and the distribution of the integral of heat for each peak is shown in Figure 4 for exp5.

In this way, it is possible to calculate both the enthalpy change for the complete melting at $5^{\circ} \mathrm{C}$. $\min ^{-1}$ ( $\Delta \mathrm{H}_{5}$ tot in joules per gram) and the energy distribution (as percentage of the total energy involved) in the three different phenomena. Results are shown in Table 2.

Surprisingly, precursor powders rich in $\mathrm{Bi}$ present higher enthalpy values than those with lower $\mathrm{Bi} /(\mathrm{Sr}+\mathrm{Ca})$ ratios, which is the opposite trend to that presented at $50^{\circ} \mathrm{C} \mathrm{min}^{-1}$. It is worth comparing the trends presented for total enthalpy and the amount of energy involved in the main peak $\left(885^{\circ}\right.$ $895^{\circ} \mathrm{C}$ ) as a function of initial atomic composition, Figure 5. For high enthalpy values, lower proportions of energy involved in the third peak are found, which indicate that the second endothermic phenomenon is the responsible of the $\Delta \mathrm{H}_{5}$ trend.

This striking result may have two different causes:

- Hypothesis a): the precursor comprises different chemical species (which in fact is confirmed by SEM analysis) with successive melting points, and different enthalpies of fusion, or,

- Hypothesis b): there is certain degree of dissolution of solid species in a liquid phase that behaves as a fluxing agent.

Hypothesis (a). Taking into account that precursor exp9 presents only one fusion peak, the enthalpy of fusion and onset temperature (melting point) of a possible specie poor in Bi that melts between $885^{\circ}$ and $890^{\circ} \mathrm{C}$ can be accurately calculated: $\mathrm{T}_{\text {onset }}=889^{\circ} \mathrm{C}, \Delta \mathrm{H}_{\text {third }}=103 \mathrm{~J} \mathrm{~g}^{-1}$. Provided that the energy distribution, initial weight and the enthalpy of third peak are known, it is possible to calculate the mass percentage for each sample that melts in the temperature range between $885^{\circ}$ and $895^{\circ} \mathrm{C}\left(\% \mathrm{Wt}_{\mathrm{third}}\right)$. The relationship of the obtained values and the initial composition is seen in Figure 6. Once the mass involved in the third peak has been calculated, the values of mass involved in the low temperature peaks are obtained; on the other hand, the amount of energy (in joules) in the temperature range of $865^{\circ}$ to $885^{\circ} \mathrm{C}$ is known, so it is possible to calculate the theoretical enthalpy change in the second

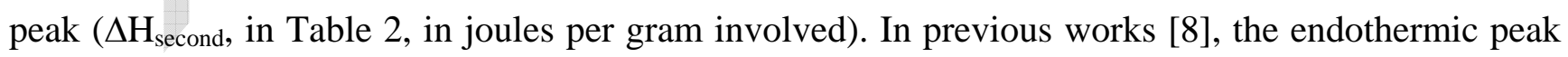
before the main one had been considered as the fusion peak of the Bi-2201 phase. In that case, all the energies calculated would have the same value or would be at least quite close. Provided that $\Delta \mathrm{H}_{\text {second }}$ 
varies with composition, it can be inferred that the endothermic peak that appears between $875^{\circ}$ and $885^{\circ} \mathrm{C}$ cannot be assigned to the fusion peak of a single phase.

Hypothesis (b). It is generally agreed that the enthalpy change of the reaction supported by the liquid phase is less than that of the reaction between solid-state reactants [17]. In this way, the proportion of $\mathrm{Bi}$ in the initial precursor composition could govern the formation of final species in the annealed rod: $\mathrm{Bi}$ rich precursors tend to form compounds that melt and behave as fluxing agents that dissolve part of the mass at lower temperatures. On the other hand, those precursors with decreasing proportions of $\mathrm{Bi}$, tend to form higher proportions of that specie whose melting point is $889^{\circ} \mathrm{C}$, or at least, there is less proportion of that 'fluxing' specie. Figure 7 shows the trend presented for the enthalpy change in the second peak in joules per gram of mass involved as a function of initial composition of precursors. The main information of this figure is that for those precursors poor in $\mathrm{Bi}$, the small proportion of mass that reacts between $875^{\circ}$ and $885^{\circ} \mathrm{C}$ (second peak) is mainly involved in solid state dissolution, whereas for Bi-rich precursor, the mobility of reactants is accelerated by the formation of a liquid phase [13].

In this way, after the results obtained by differential calorimetry, the production of superconductor materials in fast heated systems (for instance, laser floating zone) is related to phase melting and partial dissolution, whereas for those production methods involving long low temperature exposures (calcination), solid state dissolution pays an important role in final phases formation. These differences in formation mechanisms could be the responsible of the final electrical properties.

\section{Ionic rearrangement throughout DSC.}

Additional mechanistic inferences can be obtained from DSC of precursor in the low temperature range. The first endothermic peak in Figure 4, between $840^{\circ}$ and $860^{\circ} \mathrm{C}$, which is not very important in terms of energy absorbed nor mass involved, presents a distinctive profile. Apart from the flat shaped peak, the line is comprised of small but well defined successive peaks which indicate independent endothermic phenomena. We have not found in the literature the characterisation of this phenomenon, probably due to the high definition of our DSC detector (acquisition time in the software was 0.5 sec point $^{-1}$ ). In Figure 8, it is possible to see this behaviour for precursors exp1, 2, 3, 4, 5, 6 and 7. On the other hand, precursors with low $\mathrm{Bi}$ content do not show this behaviour at low temperatures. It is commonly believed that ionic rearrangement resulting in 2201 lattice formation occurs before the solid state dissolution, so these peaks would be their thermodynamic image. Slower heating ramps and isothermal stages are used to explore this hypothesis. Figures 9 and 10 show the 
behaviour of selected materials subjected to heating rates of $0.1^{\circ} \mathrm{C} \mathrm{min}^{-1}$ or to isothermal steps. Small endothermic peaks can be observed in the figures for exp5, as example of Bi-rich precursors. Although energy quantification is not possible, these unique profiles could be the verification of ionic rearrangements in lattice formation when slowly heated to $860^{\circ} \mathrm{C}$. On the other hand, exp9 in Figures 9 and 10 presents a distinct peak at higher temperature, indicating that small variations in initial precursor compositions involve different lattice rearrangement. These findings are another confirmation of the great convenience of DSC in describing phase microstructure in superconductors preparation and the relationship of composition with the final properties.

\section{CONCLUSIONS}

Differential thermal analysis is a very useful technique to simulate laser fusion of ceramic precursors to prepare BSCCO superconducting materials. One of the main inferences from this study is that, at $50^{\circ} \mathrm{C} \mathrm{min}^{-1}$, the energy required for complete melting of the precursor increases as $\mathrm{Bi}$ content in the precursor decreases, but, on the contrary, at slow heating ramps, the incidence of solid state reactions involves higher energy requirements for dissolution process plus incongruent melting for Bi-rich precursors. DSC allows to determine the role of solid diffusion between $875^{\circ}$ and $885^{\circ} \mathrm{C}$ at slow heating ramps. Moreover, a heating ramp of $0.1^{\circ} \mathrm{C} \mathrm{min}^{-1}$ seems to reveal the evolution of the ionic rearrangement between $865^{\circ}$ and $875^{\circ} \mathrm{C}$ as a function of initial composition. These results are an indication that the different fabrication procedures determine the mechanism of final phase formation. 


\section{References.}

[1] H. Maeda, Y. Tanaka, M. Fukutomi and T. Asano Jpn. J. Appl. Phys. 27 (1988) 209

[2] G.F. Holland, R.L. Hoskins, M.A. Dixon, P.D. VerNooy, H.C. zur Loye, G. Brimhall, D. Sullivan, R. Cormia, H.W. Zangbergen, R. Gronsky and A.M. Stacy, Chemistry of high temperature supeconductors, D.L. Nelson, M.S. Whittingham and T.F. George, eds. ACS Symposium Series No. 351; p 102. American Chemical Society, Washington, D.C. (1987)

[3] R.S. Liu, W.N. Wang, C.T. Chang and P.T. Wu Jpn. J. Appl. Phys. 28 (1989) L2155

[4] H. Shimojima, K. Tsukamoto and C. Yamagishi, Jpn. J. Appl. Phys. 28 (1989) L266

[5] L.A. Angurel, G.F de la Fuente, A. Badía, A. Larrea, J.C. Díez, J.I. Peña, E. Martínez and R. Navarro, Studies of High Temperature Superconductors (A.V. Narlikar Ed. Nova Science Publishers Inc) 21 (1997) 1

[6] E. Natividad, J.C. Díez, J.I. Peña, L.A. Angurel, R. Navarro, J.M. Andrés and A.C. Ferrando, Physica C 372-376 (2002) 1051-1054

[7] E. Natividad, J.C. Díez, L.A. Angurel, J.M. Andrés, A. C. Ferrando and M. C. Mayoral, Physica С 383 (2003) 379-387

[8] T.G. Holesinger, D.J. Miller, L.S. Chumbley. Physica C 217 (1993) 85-96

[9] H. Liu, L.Liu, Y. Zhang, H. Yu, Z. Jin. Journal of Materials Science 34(24) (1999) 6099-6105

[10] A. Jeremie, G.Grasso and R. Flukiger. Journal of Thermal Analysis 48 (1997) 635-645

[11] P. Strobel, W. Korczak and T. Fournier Physica C 161 (1989) 167-174

[12] J.L. Jorda, Journal of Thermal Analysis 48 (1997) 585-596

[13] H.S. Kim, R.A. Jeoung, G.J. Lee, D.H. Lee, K. Ahn, K.H. Kim. Materials Chemistry and Physics 56 (1998) 147-152

[14] P. Majewski, J. Mater. Res. 15 (2000) 854-870

[15] E. Natividad, PhD Thesis, University of Zaragoza 2002

[16] M.C. Mayoral, M.T. Izquierdo, J.M. Andrés, B. Rubio. Thermoquimica Acta 373 (2001) 173180

[17] S. Scheurell, M. Feist, E. Kemnitz. Eur. J. Solid State Inorg. Chem. 32 (1995) 539-555

[18] L.A. Angurel, J.C. Díez, E. Martínez, J.I. Peña, G.F de la Fuente and R. Navarro, Physica C 302 (1998) 39-50 
Tables.

Table 1. Atomic composition of precursors and $J_{c}^{\text {eng }}$ presented for the final annealed rod for each trial.

\begin{tabular}{llllcr}
\hline trial & $\mathrm{Bi}$ & $\mathrm{Sr}$ & $\mathrm{Ca}$ & $\mathrm{Bi} / \mathrm{Sr}+\mathrm{Ca}$ & $J_{C}^{\text {eng }}\left(\mathrm{A} / \mathrm{cm}^{2}\right)$ \\
\hline 1 & 2 & 2.09 & 1 & 0.65 & 705 \\
2 & 2.21 & 2.09 & 1.1 & 0.69 & 414 \\
3 & 2 & 1.89 & 0.91 & 0.71 & 531 \\
4 & 1.81 & 1.72 & 1 & 0.67 & 526 \\
5 & 2.21 & 1.91 & 1.01 & 0.76 & 190 \\
6 & 2 & 1.9 & 1 & 0.69 & 373 \\
7 & 1.81 & 1.98 & 0.99 & 0.61 & 889 \\
8 & 1.81 & 1.72 & 0.87 & 0.70 & 1515 \\
9 & 1.64 & 2.01 & 0.99 & 0.55 & 1067 \\
10 & 1.56 & 1.79 & 0.87 & 0.59 & \\
\hline 11 & 1.87 & 1.95 & 0.92 & 0.65 & \\
\hline
\end{tabular}


Table 2. Enthalpy change for the complete melting at $5^{\circ} \mathrm{C} \cdot \min ^{-1}\left(\Delta \mathrm{H}_{5}\right.$ tot $)$ and the energy distribution (as percentage of the total energy involved) in the three different phenomena, as a function of initial composition.

\begin{tabular}{|c|c|c|c|c|c|c|}
\hline exp & $\mathrm{Bi} / \mathrm{Sr}+\mathrm{Ca}$ & $\Delta \mathrm{H}_{5}$ tot $(\mathrm{J} / \mathrm{g})$ & \%energy & \%energy & \%energy & $\Delta \mathrm{H}_{\text {second }}(\mathrm{J} / \mathrm{g})$ \\
\hline & & & peak 1 & peak 2 & peak 3 & (theoretical) \\
\hline 1 & 0.65 & 128.8 & 2.17 & 26.30 & 71.5 & 135.4 \\
\hline 2 & 0.69 & 120.0 & 8.99 & 32.16 & 58.8 & 99.4 \\
\hline 3 & 0.71 & 132.2 & 2.75 & 49.24 & 48 & 153.1 \\
\hline 4 & 0.67 & 119.2 & - & 30.74 & 69.3 & 175.2 \\
\hline 5 & 0.76 & 128.8 & 7.18 & 59.23 & 33.6 & 141.9 \\
\hline 6 & 0.69 & 115.0 & - & 41.73 & 58.3 & 151.1 \\
\hline 7 & 0.61 & 118.1 & - & 14.66 & 85.3 & 212.7 \\
\hline 8 & 0.70 & 112.5 & - & 27.70 & 72.3 & 166.1 \\
\hline 9 & 0.55 & 103.0 & - & - & 100 & - \\
\hline 10 & 0.59 & 109.0 & - & 9.29 & 90.7 & - \\
\hline 11 & 0.65 & 128.3 & 0.91 & 19.76 & 79.3 & 243.1 \\
\hline
\end{tabular}




\section{Caption of Figures.}

Figure 1. Heat flow profiles (in arbitrary units) for exp5, exp7 and exp9 precursors at $50{ }^{\circ} \mathrm{C} \min ^{-1}$ heating ramp.

Figure 2. Initial $\mathrm{Bi}$ composition and $\mathrm{Bi} /(\mathrm{Sr}+\mathrm{Ca})$ ratio of precursors versus total enthalpy change at a heating ramp of $50{ }^{\circ} \mathrm{C} \mathrm{min}^{-1}$.

Figure 3. Peak temperatures vs. initial composition at $50{ }^{\circ} \mathrm{C} \min ^{-1}$ heating ramp.

Figure 4. Integral of heat flow and amount of heat for each peak for exp5 at $5{ }^{\circ} \mathrm{C} \min ^{-1}$.

Figure 5. Relationship of total enthalpy change and energy involved in third peak with initial composition for each precursor at a heating ramp of $5{ }^{\circ} \mathrm{C} \min ^{-1}$.

Figure 6. Relationship between initial composition and the mass percentage that melts in the third peak.

Figure 7. Relationship of enthalpy change in the second peak with initial composition for each precursor at a heating ramp of $5{ }^{\circ} \mathrm{C} \mathrm{min}^{-1}$.

Figure 8. DSC heat flow profile between $830^{\circ}$ and $875^{\circ} \mathrm{C}$ at $5^{\circ} \mathrm{C} \mathrm{min}^{-1}$ for several precursors.

Figure 9. DSC heat flow profile between to $550^{\circ} \mathrm{C}$ at $0.1^{\circ} \mathrm{C} \min ^{-1}$ for exp11 and exp5.

Figure 10. DSC heat flow profile for exp11 and exp5 at 120 minutes isothermal stages at steps of $10^{\circ} \mathrm{C}$ (from $100^{\circ}$ to $600^{\circ} \mathrm{C}$ ). 
Figures.



Figure 1.

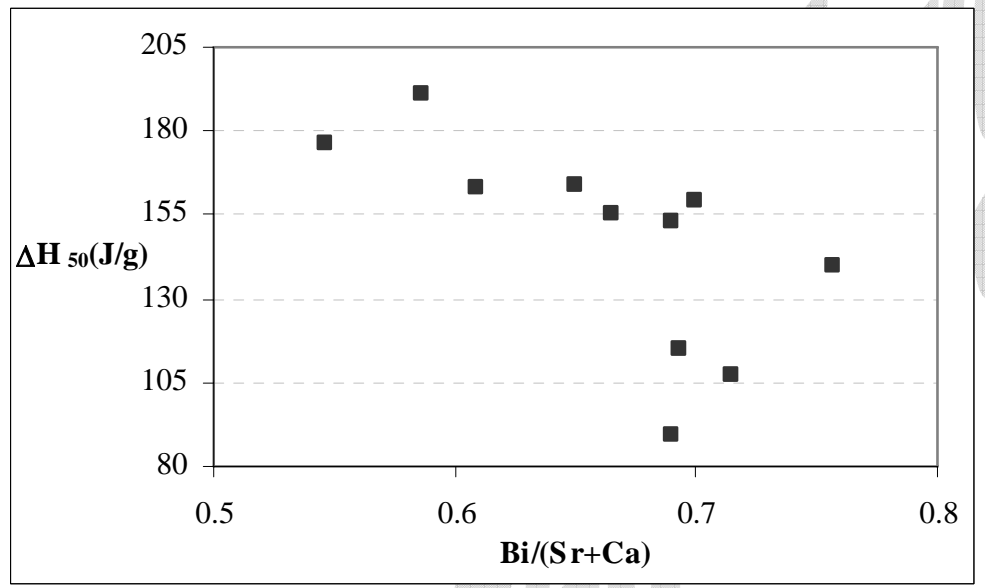

Figure 2.

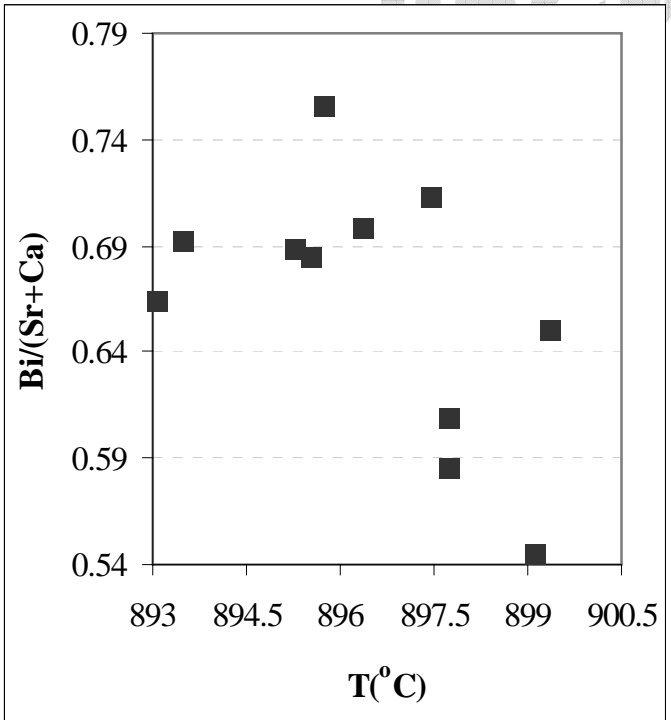

Figure 3. 


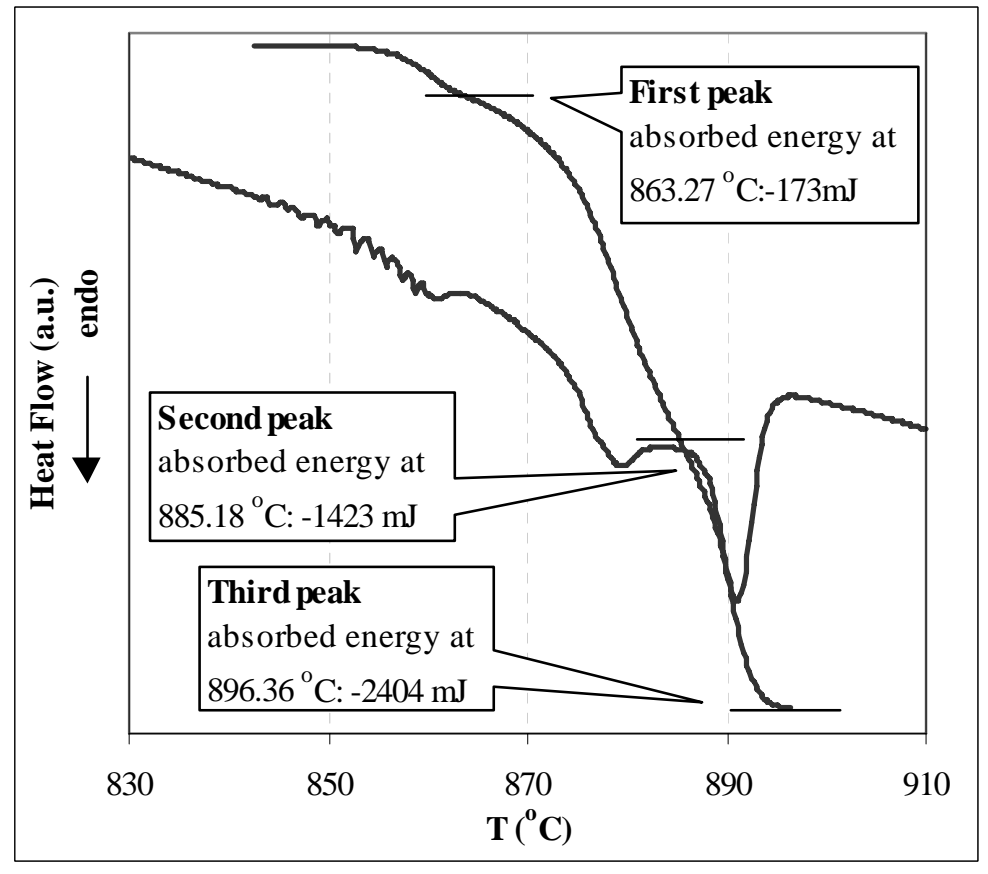

Figure 4.

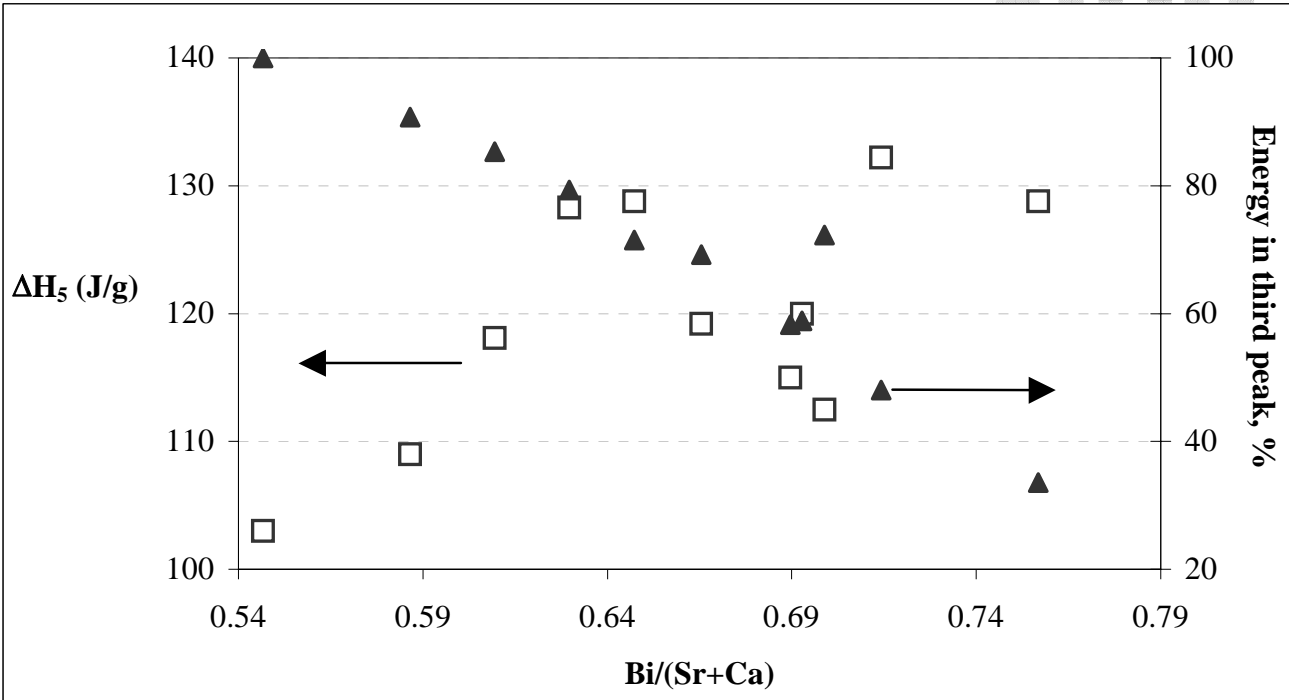

Figure 5.

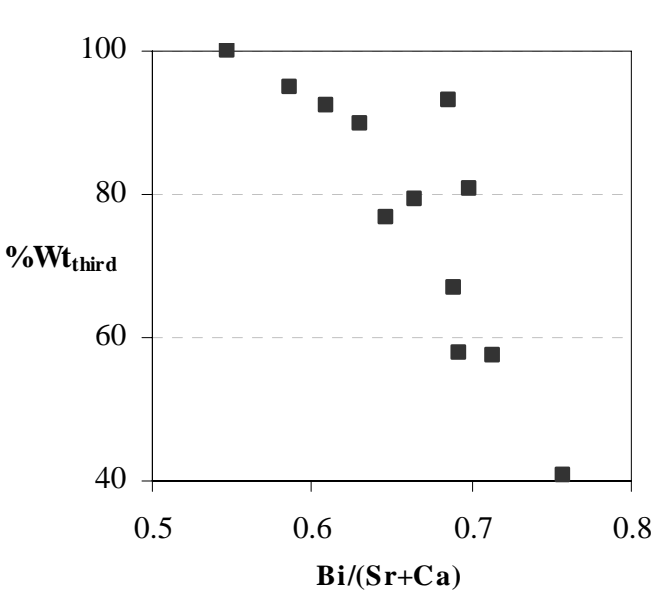

Figure 6. 


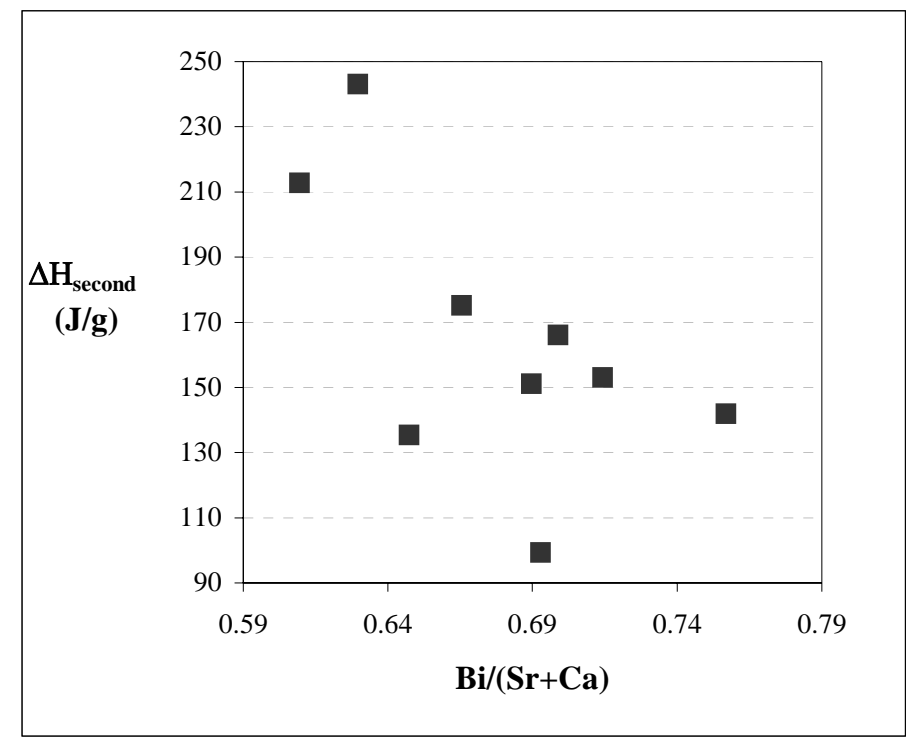

Figure 7.

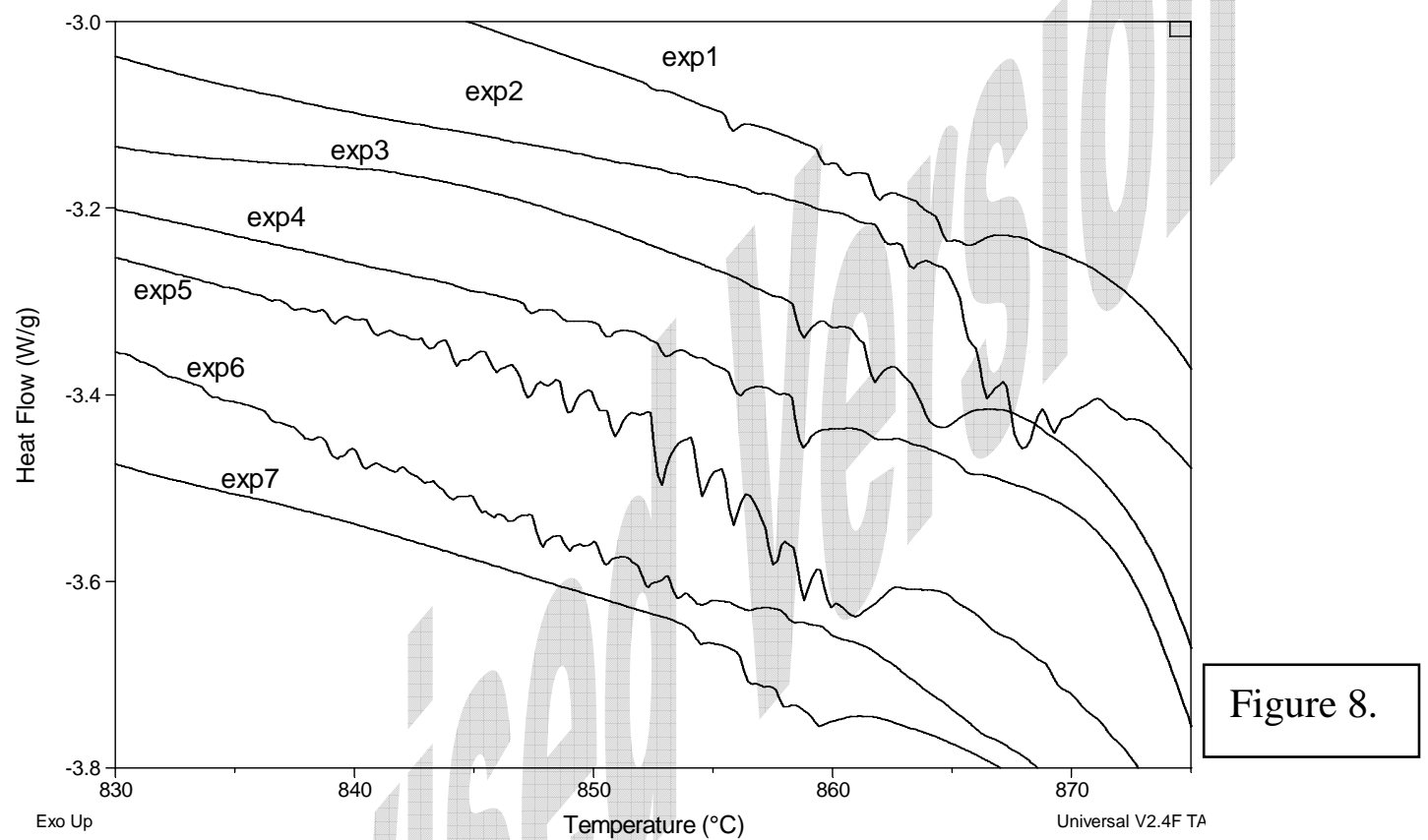




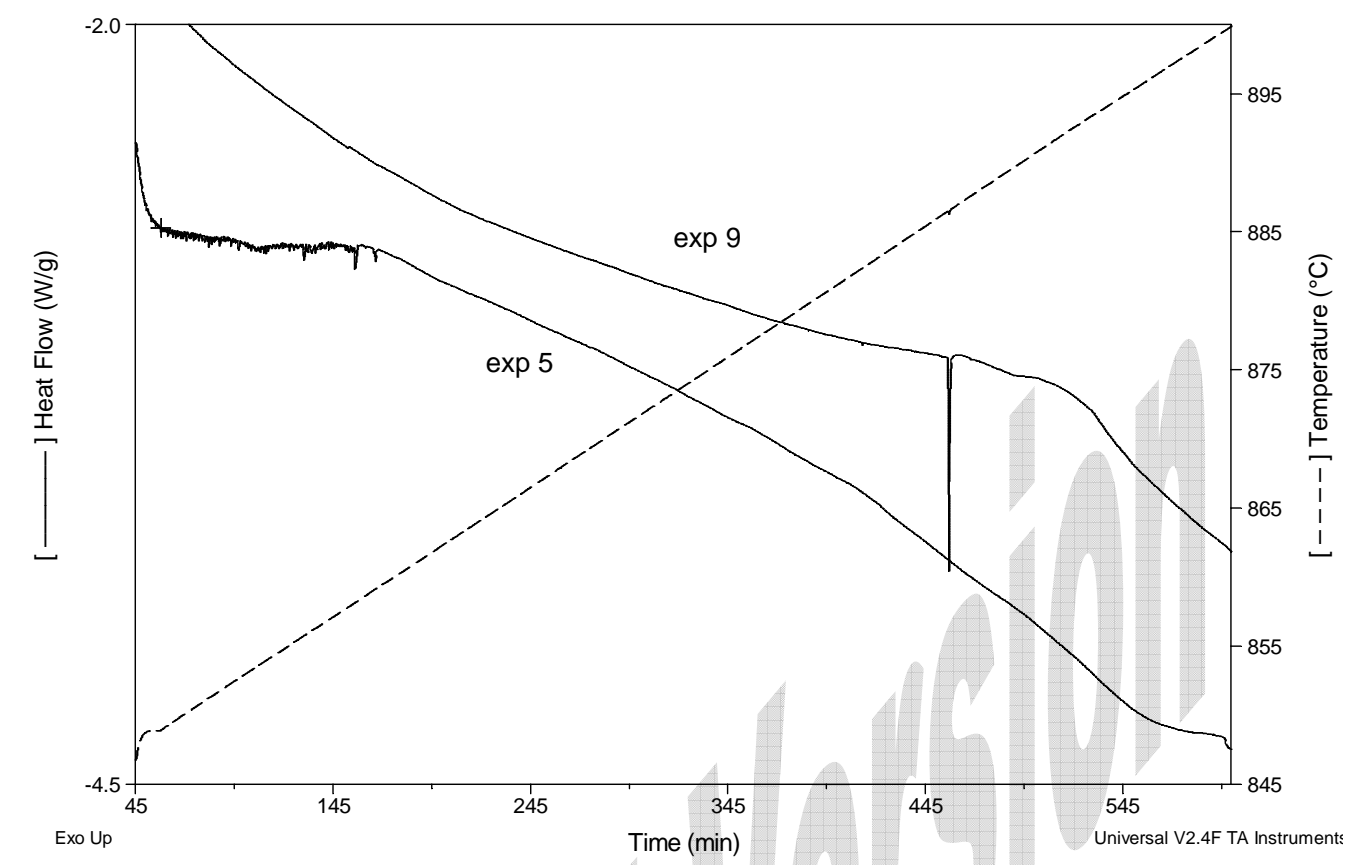

Figure 9.

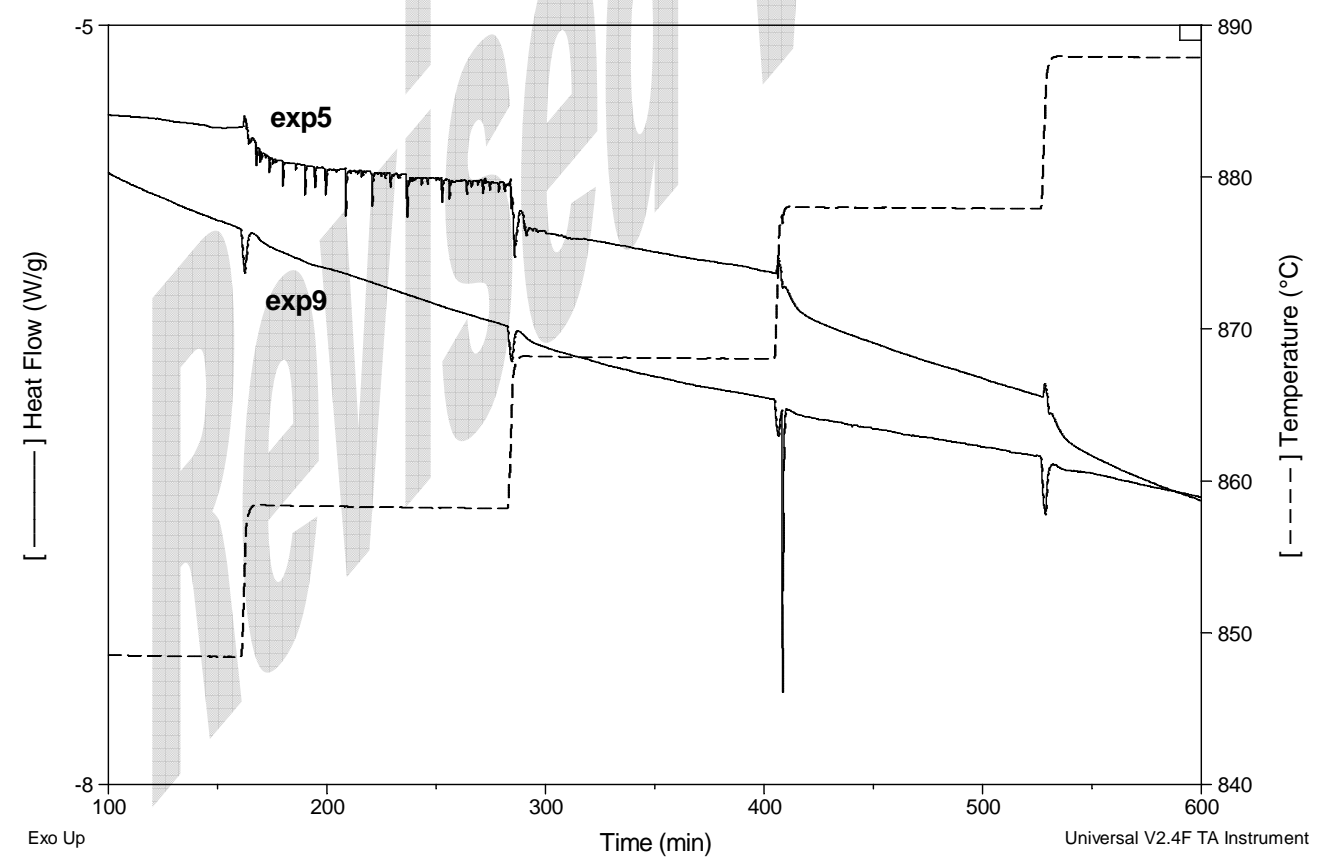

Figure 10. 